\title{
Acute Cerebral Infarct on Evolution in Middle Cerebral Artery Following Viper Snake Bite
}

\author{
Dungdung Ajit ${ }^{1}$, Singh Gaurav Kumar ${ }^{2}$ \\ Department of Medicine, RIMS, Ranchi, India
}

\begin{abstract}
Acute cerebral infarct on evolution is rare presentation of Viper snake bite. The clinical presentation depends on severity of envenomation and species of snake bite. We report a case 30 years female developed acute renal failure, disseminated intravascular coagulation followed by hemiplegia. CT scan revealed in middle cerebral artery infarction on fourth day of snake bite.Cerebral infarct could be the differential diagnosis after viper snake bite.
\end{abstract}

Keywords: Cerebral Infarct, Viper snake bite, Hemiplegia.

\section{Introduction}

In India, more than 20lakh snake bites are reported annually of which 35,000 to 50,000 people die $^{1}$.Viper bite is most common snake bite in India ${ }^{2}$.The clinical presentation includes local cellulitis, renal failure, disseminated intravascular Coagulation, haemorrhagic manifestation and neurological manifestation. Coagulopathy when present is diagnostic of viper bite ${ }^{3}$.In South Asia, viper bite have been rarely associated with cerebral infarct rather than haemorrhage ${ }^{4}$.

\section{Case Report}

A 30 years old female was brought to us, two days after an alleged history of snake bite on her right foot. The snake wasn't identified. Initially she was treated at district hospital in first twenty four hour .During admission, at our hospital patient complained of decreased urine output, difficulty in speech along with deviation of mouth. (Fig-1).Local Examinationoedema, erythema, two fang marks visible on right foot without any bleeding from the site .of bite On Neurological examination pupil bilateral reactive and bilaterally symmetrical, Patient was conscious and oriented, she had motor aphasia along with deviation of mouth left side.no evidence of motor weakness and bleeding manifestation.

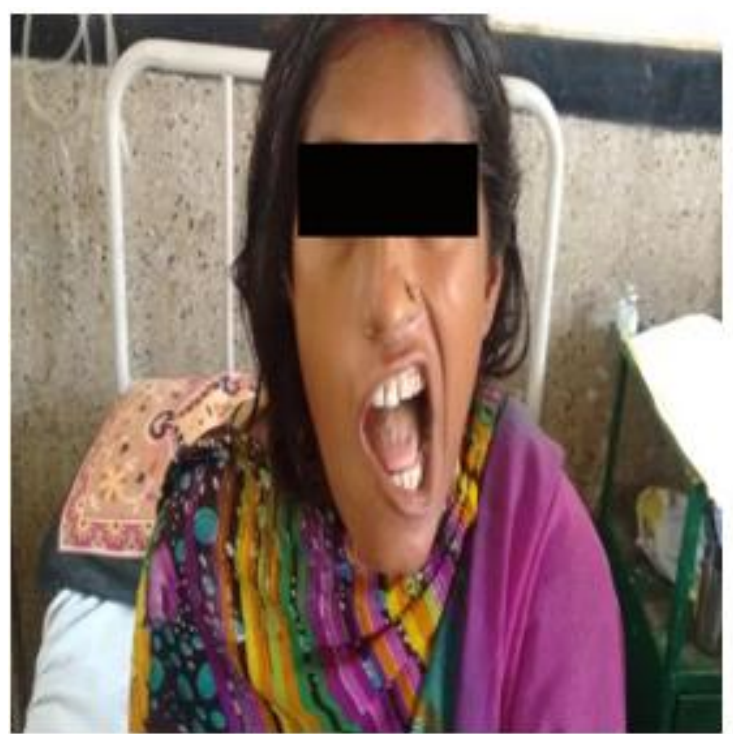

Figure 1: Deviation of angle of mouth to left

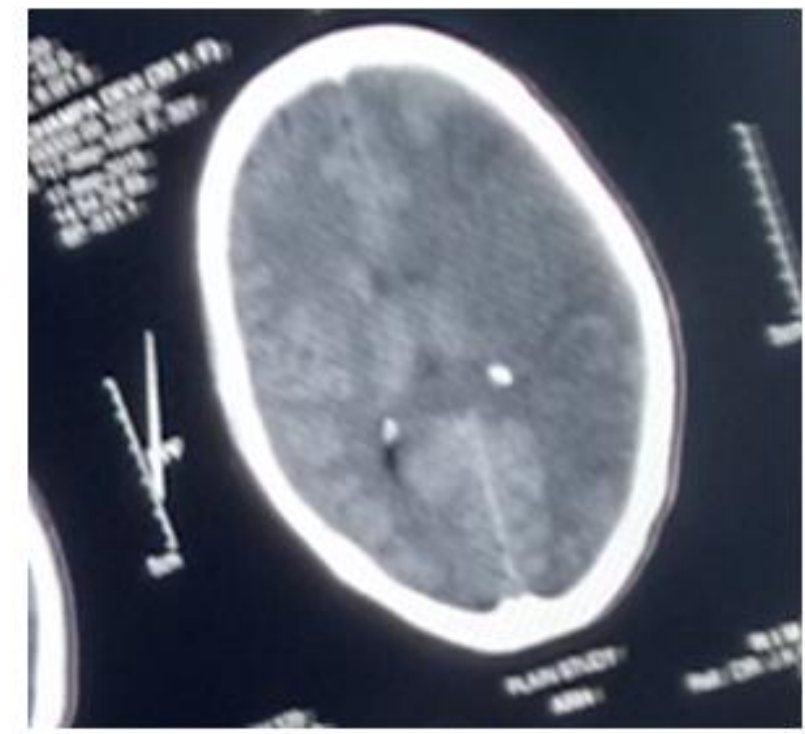

Figure 2: C.T. brain showing massive infarct in the left MCA teritory 

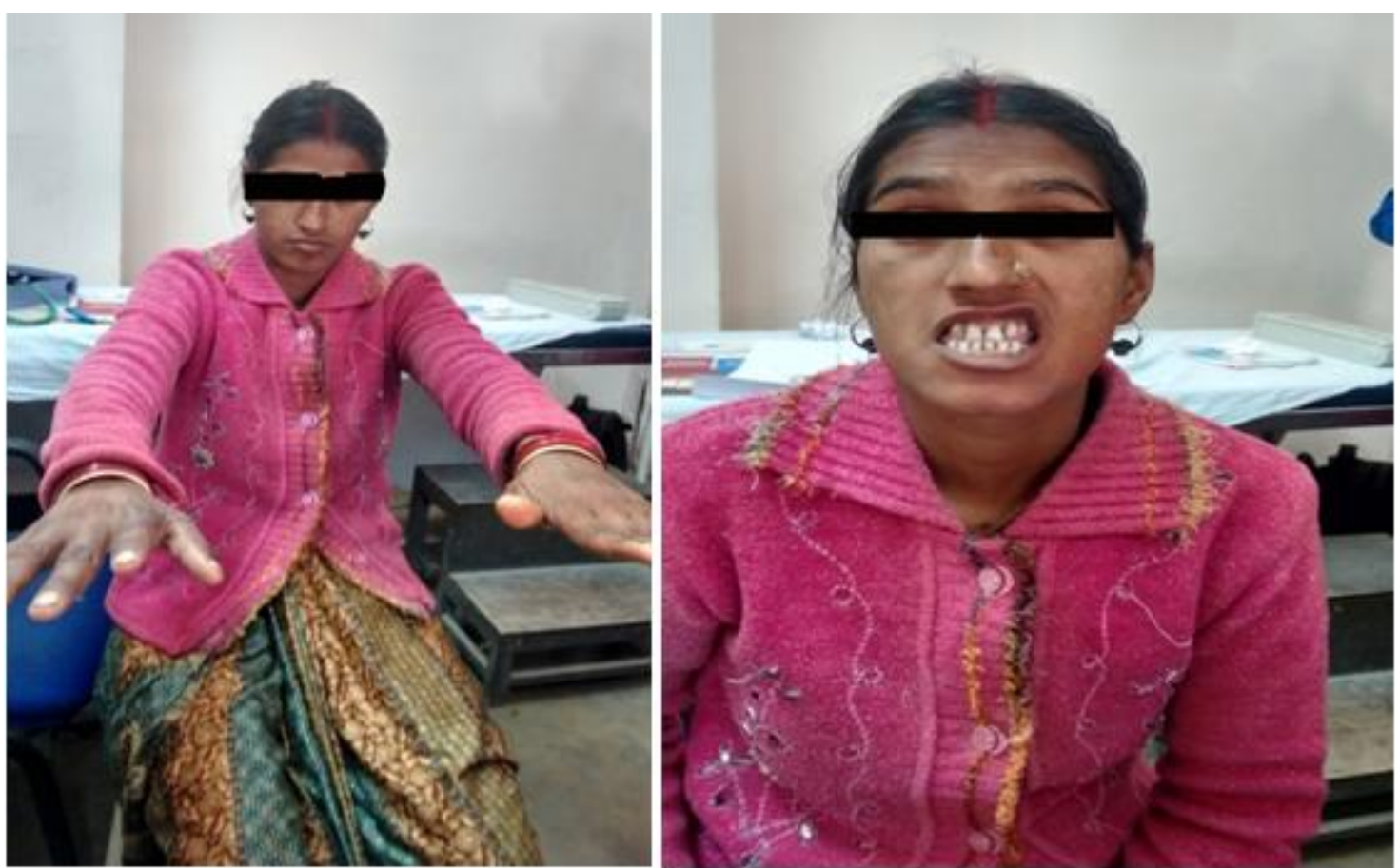

Figure 3: Residual weakness as seen after 1 month during follow up visit of the arm \& facial muscles

On investigation clotting time was prolonged to 20 minutes, microscopic haematuria were absent fibrin degrading factor more than $2700 \quad \mathrm{ng} / \mathrm{ml}[$ normal $8 \quad-135 \mathrm{ng} / \mathrm{ml}]$ thrombocytopenia $\left[75000 / \mathrm{cmm}^{2]}\right]$ withserum creatinine $1.6 \mathrm{mg}$ electro cardiographs, echocardiography, Doppler ultrasounds of both carotid artery were normal. The patient received 20 vials polyvalent anti snake venom(ASVS) over $24 \mathrm{hrs}$. and four units of fresh frozen plasma, higher antibiotics, and injectable diuretics. .However over next 2 days, she became confused developed with hemiplegia on right side. Her CT- scan revealed big infarct in left fronttempo-parietal regions affecting the lateral ventricle (figure2 ). Thus, it was a diagnosed as a case of viper snake bite with stroke on evolution which followsdisseminated intravascular coagulation and acute renal failure. Mannitol was added to above treatment regimen for 4-5 days;. antiplatelet and anticoagulant were not started in view of deranged coagulation profile. After 10 days of admission patient improved and became ambulatory but aphasia persisted. Patient was discharged with antiplatelet and physiotherapy. Patient came to follow up after 1 week of discharge with residual motor aphasia with lower limb power $5 / 5$ and upper limb 4/5.she was advised to continue aspirin and physiotherapy. patient came after one month(figure-3) her motor aphasia persist but neurological deficit improved remarkably, fibrinogen degradation product was $40.5 \mathrm{ng} / \mathrm{ml}$ blood urea $34 \mathrm{mgm} \%$ and serum creatinine became $0.6 \mathrm{mgm} \%$.

\section{Discussion}

Viper bite is most common snake bite ${ }^{2}$. The envenomation of viper bite commonly present with local cellulitis followed by abnormal coagulation ${ }^{5}$ Both procoagulation and anticoagulation effect of venom present in viper bite ${ }^{6}$.

Very few case of cerebral infarction have been reported resulting from viper bite. ${ }^{4,7-8}$. Mosquario et al, reported only
$2.6 \%$ cases that is 8 patients in 309 cases of viper bite studied. ${ }^{4}$.Bashir and jinkin reported patient in whom envenomation with Russell viperbite resulted in hemiplegia and aphasia. ${ }^{7}$ The possible cause of infarct in our patient may be due to toxic vasculitiesbyendothelial damage by viper snake bite. Betteroutcome have been reported by early ASVS treatment by Thomas et al. ${ }^{12}$

Viper venom contains complex toxin affecting haemostatic mechanism 9. In large doses it can cause massive intravascular coagulation leading to small and large vessel occlusion resulting in infarction ${ }^{10}$. Direct action of venom on endothelial cell as reported by bashir. ${ }^{7}$ Haemorrhagin the complement mediated toxic component leading to vascular spasm ,endothelial damage and increased vascular permeability resulting in vascular occlusion. ${ }^{7,8}$ Hypercoagulation due to procoagulation in venom such as arginine ,esterase and hydrolase. ${ }^{7}$ hyper viscosity is mainly caused by hypo volume and hypoperfusion secondary to hypo perfusion contributes to vascular occlusion. The infarction is not related to inherent deficiency of protein $\mathrm{c}, \mathrm{s}$ and antithrombin $3 .^{11}$

\section{Conclusion}

Cerebral infarction can be one of the differential diagnoses of early neurological deficit after viper bite and better outcome can be expected by early ASVS treatment.

\section{References}

[1] David AW. Guidelines for the clinical management of snake-bites in thesouth-east Asia region. World Health Organization, Regional Office forSouth East Asia, New Delhi: 2005. p. 1-67.

[2] Warrell DA. Snakevenoms in science and clinical medicine. 1. Russell'sviper: Biology, venom and treatment of bites. Trans R Soc Trop Med 


\title{
International Journal of Science and Research (IJSR) \\ ISSN (Online): 2319-7064
}

Index Copernicus Value (2013): 6.14 | Impact Factor (2014): 5.611

[3] Aliro ,E, , Sharma SK, Bawaskar HS,Kuch U,ChappuisF. Snake bite in south Asia: A review. Prism books PVT; 1992. p. 69-70. Alirol E, PLoSNegl Trop Dis 2010; 4:e603

[4] 4.Mosquera A,Idrovo LA, Tafur A, Del Brutto OH. Stroke followingBothrops Neurology. 2003;60:157780. [PubMed]

[5] Kulkarni ML, Anees S. Snake venom poisoning:Experience with 633 cases. Indian Pediatr1994;31:1239-43.snakebite

[6] Faridi TM, Tu AT, el-Asmar MF Effect of cerastobin,athrombinlike enzyme from Cerastes viper (Egyptiansand snake) venom, on human platelets. Haemostasis

[7] Bashir R, Jinkins J. Cerebral infarction in a young female followingsnake bite. Stroke 1985;16:328-30.

[8] Murthy JM, Kishore LT, Naidu KS..Cerebral infarction afterenvenomation by viper. J Comput Assist Tomogr 1997;21:35-7.

[9] Marsh NA. Snake venom affecting haemostatic mechanism - Aconsideration of their mechanism, practical applications and biologicalsignificance. Blood Coagul Fibrinolysis 1994;5:399-410

[10] Schwartzman RJ, Hill JB. Neurologic complications of disseminated intravascular coagulation. Neurology 1982;32:791-7

[11] Kumar V., Cortan RS., Robbins SL. Basic pathology. 5th ed. Bangalore: Murthy JM, Kishore LT, Naidu

[12] Thomas L, Tyburn B, Ketterlé J, Biao T, Mehdaoui H, Moravie V, et al. Prognostic significance of clinical grading of patients envenomed by Bothropslanceolatus in Martinique. Members of the Research Group on Snake Bite in Martinique. Trans R Soc Trop Med Hyg. 1998;92:542-5. [PubMed]

\section{Author Profile}

\begin{abstract}
Ajit Dung is Assistant Professor (medicine) R.I.M.S Ranchi, 834003
\end{abstract}

Gaurav Krsingh is Second year postgraduate.(medicine) 